\title{
Study on Technology and Programming for Comprehensive Milling
}

\author{
Zhang Rong
}

\author{
Department of Mechanical Engineering, Dalian Vocational \& Technical College, Dalian, Liaoning, \\ 116037, China \\ Lzhch11993@sina.com
}

Keywords: Milling; Processing techniques; Program

\begin{abstract}
Milling manufacturing is expounded by this paper, case analysis showed technology process and characteristic of integrated milling parts and written programmed instruction combining with the machining requirements, the usage of special or Simplified milling directives and macro in milling manufacturing procedure.
\end{abstract}

\section{Introduction}

After selecting the content of the $N C$ machining process and determine the processing of route parts, the NC machining process design can be carried out. The main task of $N C$ machining process design have further refined the processing content, cutting parameters, process equipment, the path of clamping and cutting tool for each process, which is the ready for processing program.

Determination For The Tool Path And Arrangement Working Procedure. Tool path is the movement of tool path in the entire manufacturing process, which not only includes the step of the content, but also reflects the step sequence. Pass route is one of the bases of programming. Some attention should be paid when you determine the tool path, which contain seeking the shortest processing routes, completing the final contour once, choosing the correct jump in and out of feed direction and choose the route to make workpiece deformation after processing.

Determine The Clamping Scheme. We must do our best to make programming calculation basis unifying technology data and design data. Concentrate process and reduce setup times as far as possible, which can make all waiting process surface to manufactured in clamping once as far as possible. Avoid using clamping scheme of artificial adjusting time. Action point of clamping force should be located in better rigidity.

Determine The Relative Position Of Workpiece And Cutter. It is the important to determine the relative position of the tool and the workpiece for the $C N C$ machine tools when the machining started, and the relative position is used to determined cutter-setting to achieve. The knife point means the reference point of relative position of the tool and workpiece according the knife to determine, which tend to choose the origin of parts processing as usual. It can be set on the machined part and also can be set a location which have a certain connection dimension between fixture and datum location.

Selection principle of cutters as shown below:

1)The selected cutter point make the program easy.

2)The cutter point select the position which easy to be find and easy to determine the origin of parts processing.

3)The cutter point should be selected the position which testing convenient and reliable in processing.

4)The selected cutter point should improve the machining precision.

Determine Cutting Parameter. Machined materials, cutting tool and cutting parameter are three major elements of cutting process for high efficiency of metal cutting machine tools, which determine the processing time, cutter life and processing quality. The economical and effective methods of process which should selected a reasonable cutting condition. The mechanical designers should be select according the provisions of tool life and the catalogs of machine tool when they determine the cutting parameters in each process. They can also using the analogy to determine the 
cutting parameter, which combined with the actual experience. It must be ensure the tool can be processed a part fully and ensure the tool life can be used not less than an operating crew or at least not less than the work time of half operating crew when you select the cutting parameters.

Because of back cutting depth is mainly limited by the machine tool stiffness, the should make the back cutting depth is equal to the process's machining allowance under the machine tool stiffness allowing, which can reduce the cutting times and improve processing efficiency. Because the NC processing's finish machining allowance is less than the common machine tool's machining allowance, the finish machining allowance should be enough for the parts need higher surface quality and precision.

\section{Example Analysis}

We can use the acrylic blank that the specifications is $80 \mathrm{~mm} \times 80 \mathrm{~mm} \times 15 \mathrm{~mm}$ to write the processing program and processing, which containing the inner, outer contour and hole series of comprehensive milling parts as shown in fig1.

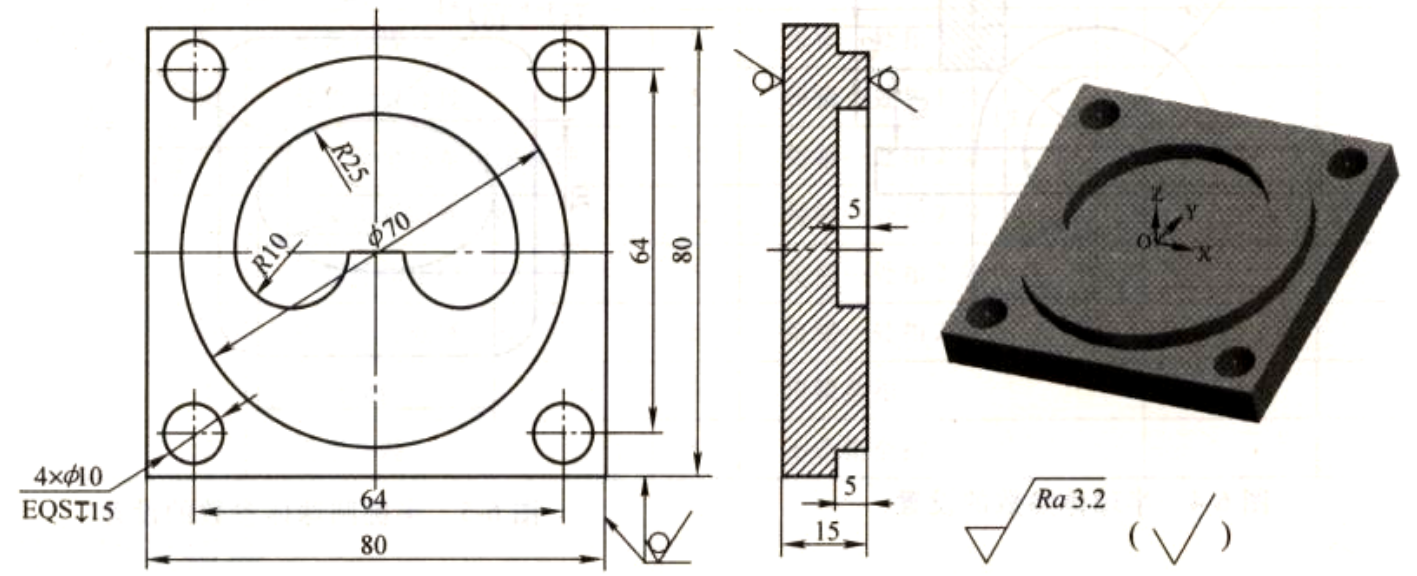

Fig.1 Comprehensive milling parts

Determine Processing Technology.1)Processing way is vertical CNC milling

2)Machining equipment is $S V-8 M N C$ milling machine 。

3)Blank material acrylic's specifications is $80 \mathrm{~mm} \times 80 \mathrm{~mm} \times 15 \mathrm{~mm}$

4)Machining tool contain $10 \mathrm{~mm}$ diameter of carbide end-mil(T01) and $10 \mathrm{~mm}$ diameter of $\operatorname{bit}(T 02)$.

5)Processing route There have allowance of $1 \mathrm{~mm}$ after rough milling, which should be removed in process of finish milling. A same knife can have many tool radius compensation, and use different tool radius compensation can remove more finish milling, while achieving multiple roughing the workpiece. The process line shown in fig 2.

6)Choose Clamp Clamping parts with flat-nose pliers.
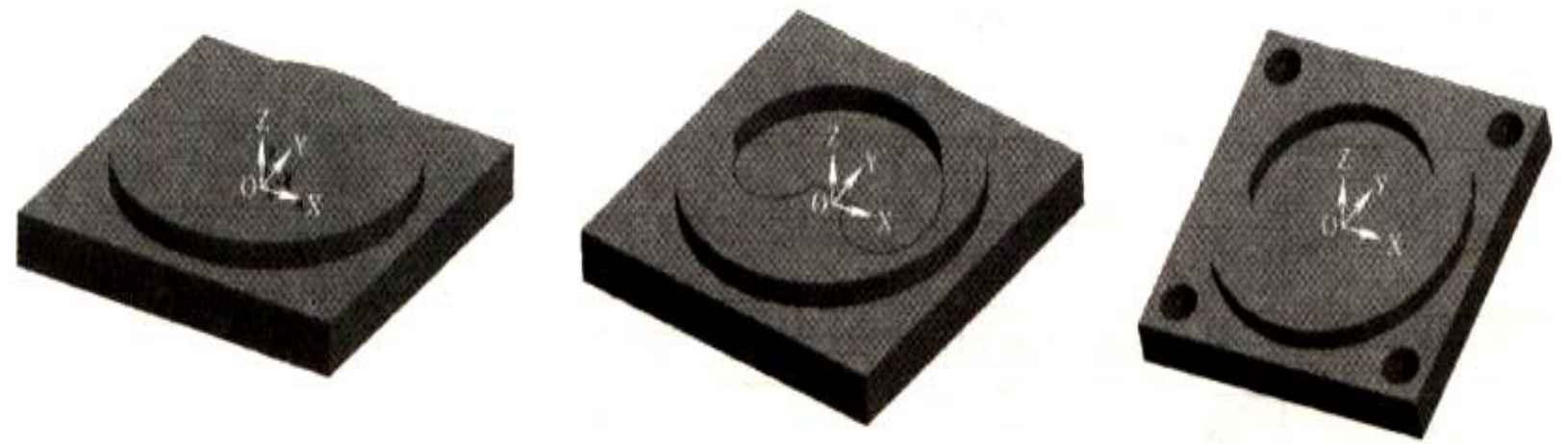

Fig. 2 The processing route of comprehensive milling

Fill In The Craft Card. CNC machining technique card see Table 1, NC machining tool card see Table 2. 
Table1 CNC machining technique card

\begin{tabular}{|c|c|c|c|c|c|c|c|}
\hline \multicolumn{2}{|l|}{$\begin{array}{l}\text { CNC } \\
\text { card }\end{array}$} & machining technique & \multicolumn{2}{|c|}{ operation number } & \multicolumn{3}{|c|}{ use equipment } \\
\cline { 5 - 8 } $\begin{array}{l}\text { Step } \\
\text { No. }\end{array}$ & $\begin{array}{l}\text { step } \\
\text { content }\end{array}$ & $\begin{array}{l}\text { machining } \\
\text { surface }\end{array}$ & $\begin{array}{l}\text { Tool } \\
\text { number }\end{array}$ & $\begin{array}{l}\text { Tool } \\
\text { specification// } \\
\text { mm }\end{array}$ & $\begin{array}{l}\text { Spindle } \\
\text { speed/(r/mm })\end{array}$ & $\begin{array}{c}\text { feed/(mm/ } \\
\text { min })\end{array}$ & $\begin{array}{c}\text { back engagement of } \\
\text { the cutting edge /mm }\end{array}$ \\
\hline 1 & $\begin{array}{c}\text { milling } \\
\text { cylinder }\end{array}$ & side & T01 & $\varphi 10$ end mill & 1000 & 50 & 5 \\
\hline 2 & $\begin{array}{l}\text { milling } \\
\text { cavity }\end{array}$ & side & T01 & $\varphi 10$ end mill & 1000 & 50 & 5 \\
\hline 3 & drilling & surface & T02 & $\varphi 10$ bit & 600 & 100 & - \\
\hline
\end{tabular}

Table2 NC machining tool card

\begin{tabular}{|c|c|c|c|c|}
\hline Serial number & No. & Tool name & Specifications & Quantity \\
\hline 1 & T01 & End mill & $\varphi 10$ & 1 \\
\hline 2 & T02 & Bit & $\varphi 10$ & 1 \\
\hline
\end{tabular}

Machining Programming Process. Determine the Workpiece Coordinate. As shown in fig3,select the intersection of parts the symmetry axis as the origin of workpiece coordinate system of $X$ axis and $Y$ axis, and select workpiece surface as the origin of $Z$ axis, then create workpiece coordinate system.

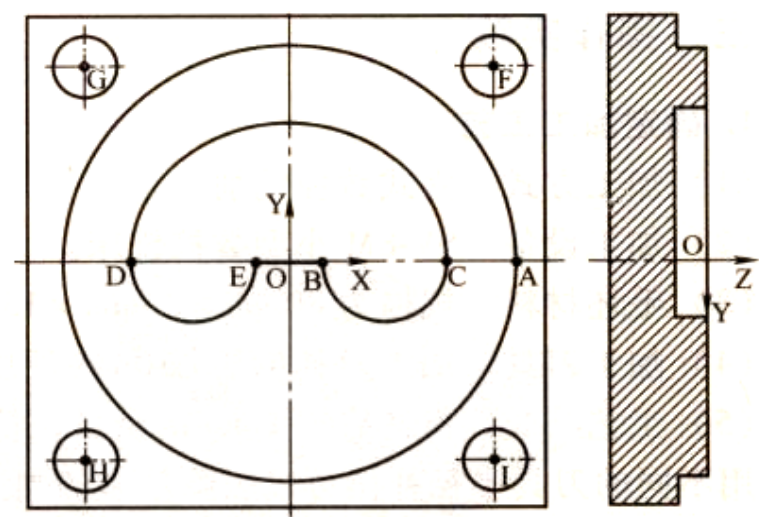

Fig.3 Comprehensive milling the workpiece coordinate system

Determine the base Point Coordinate. According to figure 3, After calculating the coordinates of each point is $A(35,0), B(5,0), C(25,0), D(-25,0), E(-5,0), F(32,32), G(-32,32), H(-32,32), I(32,-32)$ 。

Fill in the NC Machining Program. The machining program is shown as Table 3.

Input Program. Through the operation panel, input the processing procedures in the mode of "EDIT".

Clamping And Tool.1)The flat-nose plier mounted on the work table of the machine, find the fixed jaw of the flat- nose plier, which make the fixed jaw parallel to the table of $X$ axis. 2)Make the workpiece grip on the machine vise. 3)Using master bar and gauge tool to get the value of $X, Y, Z$ and then entered into the G54.

Processing And Testing. It will be processed automatically after program verification and cutting location simulation are structured right. The machine will be stop automatically after the program execution to the end and the return to the setting height.

Use vernier caliper to measure the size of parts, which can adjust tool repair and execute the program of machining workpiece again until it meets the requirements.

\section{Conclusion}

As the rapid development of high speed machining technology, the development trend of CNC milling machine reflect on the precise processing which will have a breakthrough. Through optimize the machine structure and refining the manufacturing and assembly, refinement of CNC 
system and servo control, using high precision components and the application of temperature and vibration error compensation technology, which can improve the geometric accuracy and movement precision machine tool processing and then reduce the shape and position error and surface roughness.

Table 3 NC program list

\begin{tabular}{|c|c|c|}
\hline \multirow{2}{*}{$\begin{array}{c}\text { Program } \\
\text { number }\end{array}$} & The processing program & Specification of program \\
\hline & $\% 0003$ & program name \\
\hline N10 & G90 G40 G21 G94 G17 & program initialization \\
\hline N20 & G91 G28 Z0 & the $\mathrm{Z}$ axis rotating reference point \\
\hline N30 & G90 G54 M03 S1000 & call the coordinate system \\
\hline N40 & G00 X0 Y0 & \multirow{3}{*}{ quick point positioning } \\
\hline N50 & $\mathrm{Z} 20$ & \\
\hline N60 & $\mathrm{X} 70 \mathrm{Y0}$ & \\
\hline N70 & G01 Z-5 F30 & back cutting depth as $5 \mathrm{~mm}$ \\
\hline N80 & G42 G01 X35 D01 & tool radius compensation right \\
\hline N90 & G03 I-35 J0 & milling $\varphi 70$ cylindrical \\
\hline N100 & G01 X70 & \multirow{2}{*}{ end milling cylindrical } \\
\hline N110 & G40 & \\
\hline N120 & G00 Z5 & \multirow{2}{*}{ feed point X0 Y10, ready for milling bore } \\
\hline N130 & G00 X0 Y10 & \\
\hline N140 & G01 Z-5 F50 & back cutting depth $5 \mathrm{~mm}$ \\
\hline N150 & G41 G01 Y0 D01 & tool radius compensation \\
\hline N160 & G01 X5 & \multirow{4}{*}{ milling cavity } \\
\hline N170 & G03 X25 R10 & \\
\hline N180 & G03 X-25 R25 & \\
\hline N190 & G03 X-5 R10 & \\
\hline N200 & G01 X5 & \multirow{2}{*}{$\begin{array}{l}\text { the end milling cavity, cancel the tool } \\
\text { compensation }\end{array}$} \\
\hline N210 & G40 G01 X0 Y10 & \\
\hline N220 & G91 G28 Z0 & back to the reference point \\
\hline $\mathrm{N} 230$ & M05 & \multirow{2}{*}{ program halt } \\
\hline N240 & M00 & \\
\hline N250 & M03 S600 & spindle drive, speed of $600 \mathrm{r} / \mathrm{min}$ \\
\hline N260 & G00 Z20 & achieve safe altitude \\
\hline $\mathrm{N} 270$ & G83 X32 Y32 Z-18 Q5 R5 F100 & \multirow{4}{*}{ fixed drilling cycle } \\
\hline $\mathrm{N} 280$ & X-32 & \\
\hline $\mathrm{N} 290$ & Y-32 & \\
\hline N300 & X32 & \\
\hline N310 & G80 & drilling end \\
\hline N320 & G00 Z20 & return to the safe area \\
\hline N330 & M05 & \multirow{2}{*}{ end of program } \\
\hline N340 & M30 & \\
\hline
\end{tabular}

\section{References}

[1]Xiao Zhiqing. Machinery Manufacturing Base, Machinery Industry Press.2008,01.

[2]Chen Jianjun,Li Liangkai. Application of CNC Milling Point the Leads and Route[J].Metal Working (cold).2011,03.

[3]Zhong Zhi. Methods to Improve the Accuracy of CNC Milling [J].Mechanical Engineer.2011 07.

[4]Ren Xiaohong.CimatronE9.0 Application in NC Machining [J].Die \& Mould Industry.2011 07.

[5]Xu Yan.CNC Milling Casing Deformation Cause Analysis and Control Countermeasures[J].

Value Engineering.2011,12. 